DOI: 10.1136/annrheumdis-2017-eular.2918

\section{AB0943 SIGNIFICANCE OF MUSCLE VOLUME \& FATTY DEGENERATION OF LUMBAR PARASPINAL MUSCLE IN SPINAL IMBALANCE}

Y.-S. Park, J. Lee, J.-S. Park. Department of Orthopaedic Surgery, Hanyang University Guri Hospital, Guri city, Korea, Republic Of

Background: Spinal sagittal imbalance which is closely associated with low back pain is considered as a factor in a variety of spinal disorders.

Objectives: The present study was to determine the relationship between the sagittal imbalance and sarcopenia, especially cross sectional area (CSA) and fatty degeneration (FD) of muscle around the spine.

Methods: Overall, 165 patients are included in this study, classified by three groups according to the distance from sagittal vertical axis to posterior end of upper end plate of sacrum.

38 patients were classified as group 1 (distance $\geq 9 \mathrm{~cm}$ ), 50 and 53 patients as group 2 (distance $5-9 \mathrm{~cm}$ ) and group 3 (distance $<5 \mathrm{~cm}$ ), respectively. For measurement of CSA and FI of paraspinal muscles, five transverse T1W images of S1-S5 were obtained from PACS and measured with Adobe Photoshop 7.0 ${ }^{\circledR}$, by counting the number of pixels included in each selected muscle area. A variance analysis on average muscle surface area of those five images was done with SPSS 19.0 Windows version (SPSS Inc., Chicago, IL, USA).

Results: The average age of total patients was 69.1, average BMI was 22.57 and bone density was -2.34 (T-score)

No significant differences were detected on ages, BMI, and bone density. Each correction coefficient of multifidus, erector spinae and psoas muscle was 0.80 , 0.75 and 0.81 , respectively.

CSA of paraspinal muscles has significant differences between group I and III, II and III. Psoas has significant differences between all groups. FI has significant differences between all groups in multifidus and between I and III, II and III in erector spinae. But, psoas has no significance between three groups.

Conclusions: Authors were able to detect significant muscle atrophy in the group with severe imbalance. And degeneration of paravertebral muscle has significant increased with sagittal imbalance. Effort for preventing weakness of muscle around spine might cause influence to alignment of spine.

\section{References:}

[1] Fortin M, Lazáry À, Varga PP, McCall I, Battié MC. Paraspinal muscle asymmetry and fat infiltration in patients with symptomatic disc herniation. Eur Spine J Off Publ Eur Spine Soc Eur Spinal Deform Soc Eur Sect Cerv Spine Res Soc 2016;25:1452-9. doi:10.1007/s00586-016-4503-7.

[2] Lee SH, Park SW, Kim YB, Nam TK, Lee YS. The fatty degeneration of lumbar paraspinal muscles on computed tomography scan according to age and disc level. Spine J Off J North Am Spine Soc 2016

[1] doi:10.1016/j.spinee.2016.08.001.

Disclosure of Interest: None declared

DOI: 10.1136/annrheumdis-2017-eular.4228

\section{Paediatric rheumatology}

\section{AB0944 USE,SAFETY AND EFFICACY OF ETANERCEPT IN JIA-A SINGLE CENTRE RETROSPECTIVE STUDY FROM NORTH INDIA}

A. Shivpuri ${ }^{1}$, S. Mittal ${ }^{1}$, M. Agarwal ${ }^{2}$, S. Sawhney ${ }^{2} .{ }^{1}$ Fellow in Training, Pediatric Rheumatology; ${ }^{2}$ Consultant, Sir Ganga Ram Hospital, New Delhi, India

Background: The treatment paradigm for Juvenile Idiopathic Arthritis (JIA) has changed in last decade:Early diagnosis,objective assessment \& appropriate use of biologic response modifiers (BRMs) are common place.Etanercept (Et) is available in India for 15yrs. BRM use in developing world is fraught with challenges: cost, high burden of Tuberculosis (TB) \& retention. In view of the cost \& safety concerns regarding TB, at our centre, full dose Et is used for 3-6 mths, followed by dose tapering as tolerated.

Objectives: 1. To determine the use, safety \& efficacy of Et in JIA. 2. To determine the factors that determine responders vs non responders. 3 . To determine the factors that determine disease free survival on stopping Et

Methods: This study was done from 15thJune'15 to15thDec'16 (18mths) at Sir GangaRam Hospital. Inclusion criteria: All JIA pts who took Et for min 12 wks \& attended the outpatients during the study period. Outcome: All pts who achieved the Wallace criteria of inactive ds, clinical remission on (CRoM) or off medication within 4 months were termed as responders.

Results: Use: 46pts recd Et (29M,17F). Median (Md) age at JIA onset: 9.08yrs (1.16-16.5).Md delay to diagnosis: 4 mths (0.5-63). Md age at initiation of Et: 11.6yrs (4.25-20.3). Indications: Partial response to Intraarticular steroids/bridging steroids \& DMARD-32; Started upfront for high ds.burden: 14. Diagnoses: ERA30 (65\%), Poly JIA8 (17\%), OJIA 3 (7\%), SOJIA $3(7 \%)$ \& UJIA $2(4 \%)$. Safety: Screening: Mantoux +ve: 6, Quantiferon+ve: 2, antitubercular therapy for latent TB: 8. Side effects: 41 (88\%) had no adverse event. 5 pts - 1 each had enteric fever, varicella, uveitis, hemolysis, malaria. Follow up: Md duration of follow up-47.5 mths (2-147). Medications at last follow up: Et ongoing in 20 (43.5\%), 12 on 2nd BRM, 12 off BRM \& 2 lost to follow up. Status at last follow up: Of 37 responders -8 currently active.
Responders vs non responders: 37 responded ( 2 excluded duration $<12$ wks). In all responders drug was tapered/stopped. No demographic, clinical, lab criteria could predict responder from non responder (Table 1).

\begin{tabular}{lccc}
\hline & Responders (37/44) & Non Responders (7/44) & p value \\
\hline Md time to inactivity post Et & 9 wks $(1-52)$ & - & \\
Md time to flare & $15 \mathrm{~m}(3-63)$ & - & \\
Md duration of taking Et & $18 \mathrm{~m}(3-56)$ & $5.5 \mathrm{~m}(2-22)$ & 0.01 \\
Md Time to first taper Et & $5 \mathrm{~m}(1-34)$ & $2 \mathrm{~m}(1.5-16)$ & 0.44 \\
Median ESR & $38(4-125)$ & $63(22-125)$ & 0.08 \\
SJC $\leq 4$ jts $>4$ jts & $29(78.4 \%) 8(21.6 \%)$ & $4(57.1 \%) 3(42.9 \%)$ & 0.34 \\
TJC $\leq 4$ jts $>4$ jts & $32(86.5 \%) 5(13.5 \%)$ & $4(57.1 \%) 3(43 \%)$ & 0.10 \\
\hline
\end{tabular}

Of 37 responders, 15 (40.5\%) did not show any flare (Table 2$)$

\begin{tabular}{lccc}
\hline & Flared (22/37) & Never flared (15/37) & p value \\
\hline Md time to inactivity post Et & 11 wks $(1-36)$ & 6 wks $(2-52)$ & 0.43 \\
Md time to flare & $15 \mathrm{~m}(3-63)$ & $18 \mathrm{~m}(3-33)$ & 0.74 \\
Md duration of Et & $17.5 \mathrm{~m}(3-53)$ & $25 \mathrm{~m}(6-56)$ & 0.64 \\
Md Time to first taper & $5.5 \mathrm{~m}(1-12)$ & $4 \mathrm{~m}(2-34)$ & 0.58 \\
Md time to stop steroids & $3 \mathrm{~m}(1-12)$ & $2 \mathrm{~m}(1-4)$ & 0.16 \\
Median ESR & $28(4-120)$ & $45(15-125)$ & 0.29 \\
$\mathrm{SJC} \leq 4$ jts $>4$ jts & $17(77.3 \%) 5(22.7 \%)$ & $12(80 \%) 3(20 \%)$ & 1 \\
$\mathrm{TJC} \leq 4$ jts $>4$ jts & $19(86.4 \%) 3(13.6 \%)$ & $13(86.7 \%) 2(13.3 \%)$ & 1 \\
\hline
\end{tabular}

Disease free survival on Et: Of 37 responders, 22 flared. No factors could predict flare in pts who recd tapering Et dose or after stopping Et. Some needed repeat cycles of Et/2nd BRM. Kaplan Meier curve of responders confirmed that no pt would be flare free at $63 \mathrm{mth}$ of follow up.

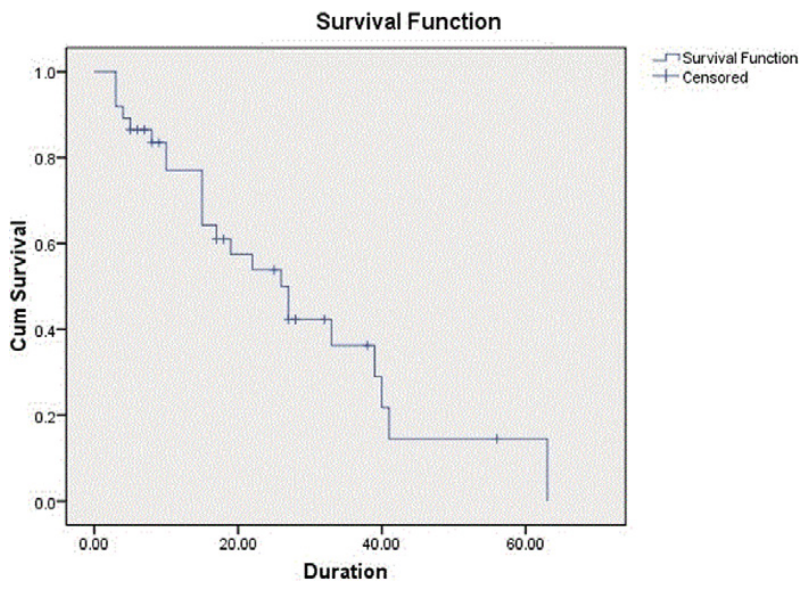

Conclusions: Et is safe to use \& had no adverse events in $89 \%$. Needed most for ERA. Effective in $84 \%$. On using shortterm Et, $59 \%$ flared either on tapering/stopping. These pts responded to reinitiation of Et/BRM. On long term follow up (63mth) there were no flare free pts.

Disclosure of Interest: None declared

DOI: 10.1136/annrheumdis-2017-eular.4892

\section{AB0945 COHORT STUDY OF 112 PATIENTS WITH JUVENILE IDIOPATHIC ARTHRITIS DURING TRANSITION FROM PEDIATRIC TO ADULT CARE}

A.-C. Debrach ${ }^{1}$, A. Beaumel ${ }^{2}$, A. Rougelot ${ }^{2}$, J.-P. Larbre ${ }^{2}$, M. Couret $^{1}$, F. Coury ${ }^{2} \cdot{ }^{1}$ Rheumatology, CHUV, Lausanne, Switzerland; ${ }^{2}$ Rheumatology, HEL, Lyon, France

Background: Juvenile idiopathic arthritis (JIA) is the most common chronic inflammatory arthritis in children. The International League of Associations for Rheumatology 2001 (ILAR) classification includes 7 subgroups: systemic JIA, polyarticular JIA, oligoarticular JIA, enthesitis related arthritis (ERA), psoriatic arthritis and undifferentiated arthritis. Most paediatric inflammatory arthritides persist into adulthood. Therefore, a transition from paediatric to adult rheumatology is a necessary step. Transition is defined as an active process by which a young patient with a chronic disease develops skills and resources to gradually take control of their condition. The transition phase should be anticipated and structured because of the risk of failure in monitoring. However difference in classification criteria in paediatric and adult rheumatology can cause significant difficulty for adult rheumatologists.

Objectives: The aim of this study was to determine the characteristics of juvenile-onset arthritis seen during the transition period and to compare paediatric classification criteria to those of adults.

Methods: A retrospective bi-centre study was performed. Patients with JIA according to ILAR classification were included and had a consultation at transition. JIA classification criteria were compared to ACR/EULAR 2010 criteria 